\title{
Environmental Coordination: Reneging and Transaction Costs
}

\author{
Jan-Erik Lane \\ Public Policy Institute, Belgrade (fellow)
}

\begin{abstract}
In the well-known Stern Review from 2006, global warming and climate change was described as the largest externality in the known history of mankind. When externalities take on a planetary scale, then costs will show up in various countries sooner or later, like now China, the Pacific Islands and Western US as well as India for instance. The core of the difficulty of counter-acting the process of poisening the atmosphere through the emission of greenhouse gases is the set of problems that governments encounter when they attempt collective action through coordination. These difficulties are well anaysed in game theory, but the lessons have no been drawn upon in the many international meetings aimig to tackle climate change. The tone is now optimistic ahead of the next major reunion in Paris end of this year, but it is not likely that the government of the countries of planet Earth will overcome the dismal logic of collective action, viz. reneging and tranaction costs.
\end{abstract}

Key Words: logic of collective action, free riding, tragedy of the commons, promises-reneging, unanimity and transaction costs, greenhouse gases: level and growth, affluence or GDP.

\section{INTRODUCTION}

Ecological capital is declining year in and year out, because nobody owns it - constituting a huge set of common pools. To measure the decrease in global ecological capital is far more cumbersome a task than to measure economic capital in the conventional sense. Yet, ecological capital is more tangible and easier to estimate than the recently much debated form of capital in the social sciences, viz. social capital or trust, which remains elusive and difficult to pin down in an index.

Concerning the decline in global environmental capital, one may adduce recent evidence about various phenomena, like the following:

- The increase in the number of endangered animals as well as the reduction in the number of species;

- The overfishing of lakes, seas and oceans;

- The increased pollution of the oceans including acidification;

- Increasing temperature in the oceans and sees;

- The concentration of human population in huge urban sites without proper sanitation and access to fresh water;

- The slow vanishing of the rain forests around the globe and the huge forests in Siberia;

- The steady growth of desert areas;

- The shrinking of large lakes;

- The growing fresh water shortages - draughts;

- The pollution of the atmosphere by greenhouse gases, leading to climate change and global warming.

Here, I will discuss the last item in the list above, in particular why coordination failure is likely with regard to the efforts at a planet climate policy, halting global warming, which is probably 
the most dangerous type of decline in ecological capital. Global warming propels strongly the other major types of environmental destruction listed above.

\section{COORDINATION AND COLLECTIVE ACTION BY GOVERNMENTS}

The somewhat 190 governments of the world come together under the UN climate change program or the G20 group of nations, representing around 70 per cent of global population, meet to discuss ecological policy-making. They have to overcome the inherent difficulties in collective choice, analysed in mainstream game theory, as these meetings invite a set of strategic interactions among leaders, representing the legal entity of a state.

The difficulties in global environmental policy-making appear in a model of social choice under uncertainty:

a) Who decides? When many governments come together to decide upon the goals and means of global policy, then the requirement of unanimity (consensus) is conducive to huge transaction costs;

b) The various governments differ greatly in their estimates of probabilities and outcome costs involved in the alternatives of action, meaning resilience will likely be the outcome by default;

c) Countries already hit by the consequences of global warming favour precaution to prevent even more disasters, whereas other countries prefer to wait and see resilience;

d) When preventive measures harm the prospects of economic growth, countries differ in how they trade off the two entities. Opportunistic action strategies - preference distortion, delay, reneging - come in as a major disturbance of the possibility of collective rationality;

e) If a global agreement is reached at these spectacular meetings, then the outcome will be government promises that can easily be reneged upon.

Given these hinders to a global ecology policy, it is little likely that any such coordination endeavours will succeed in time to halt the growth in carbon equivalent emissions. There will much discussion about what to do, but little consensus upon concrete policies - resilience taking precedence over precaution.

Thus, climate change is much talked about, but little concrete action is taken. It is hardly a top priority like economic development or growth for the countries with the 20-25 largest economies in the world. However, they and only they can take measures - precaution - that halt the increase in yearly emissions and start a process towards zero emissions per year. In this tragedy of the commons game, we now follow the strategy "resilience" that may give mankind the worst possible outcome in the future.

It is claimed as a major step towards global coordination of a common pool regime against the emission of greenhouse gases that the worst polluters - China and USA - have promised to start reducing their emission. But this promise has been made for the end of the 2020ies - too late! And it can always be reneged upon, with shifting political conditions.

Figure 1 shows that the emission of $\mathrm{CO} 2$ is now down somewhat in the US but up still in China. But the combined level of emissions is enormous, or some 14 gigatons in 2010! Even if the yearly increases in emissions are eliminated, the level of emissions stay too high for global sustainability. 
Figure 1. Increases in CO2 in China and the US

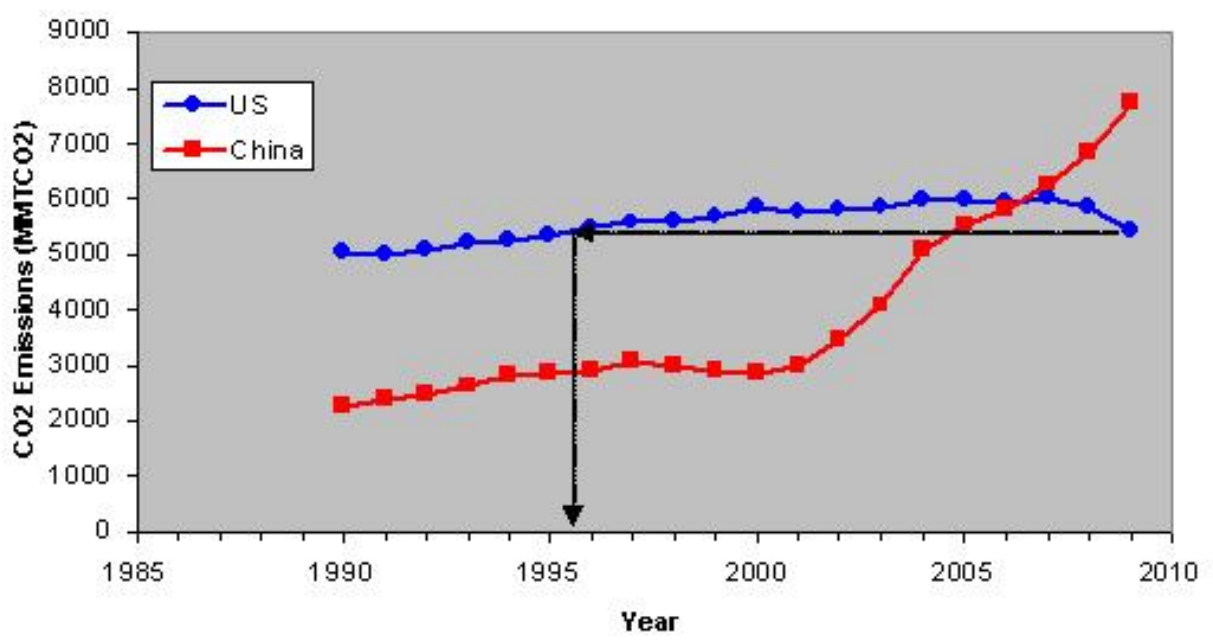

Source: Annual carbon dioxide emissions from the United States (blue) and China (red), 1990-2009 (data source, EIA).

The UK for instance speaks about an 80 per cent reduction during the 21 rst century, but how it is to be done remains to be clarified, given the strong link between cheap energy, emissions and economic development. And the level of emissions must come down already now. Yet, the recent turn to the massive use of shale oil and gas reinforces the importance of fossil fuels in the world economy, driving down the price of petrol. What basically drives global warming?

\section{THE JUGGERNAUT OF THE 21rst CENTURY: GDP, Energy and Emissions}

The inability to halt the expansion of greenhouse gases and to stem the strong increase in yearly emissions since 1980 as well as to possibly reverse the trend depends upon very strong forces in the global market economy. The consumption of cheap energy is a key element in the steady growth in total economic output. And energy is strongly linked with emissions of greenhouse gases. Mankind needs to undo these links between GDP, energy and emissions by new technology, but it will be costly and may hurt rapid economic development in countries that aim at catching-up.

\section{a) Increase in Emissions}

Given the enormous risks for mankind in relation to the probability of the worst-case scenario of climate change - 6 degrees or more, it seems negligent on the part of the world powers not to do more. The emission increases in all four types of greenhouse gases are formidable - see Figure 2.

Figure 2. Emissions growth 1979-2005

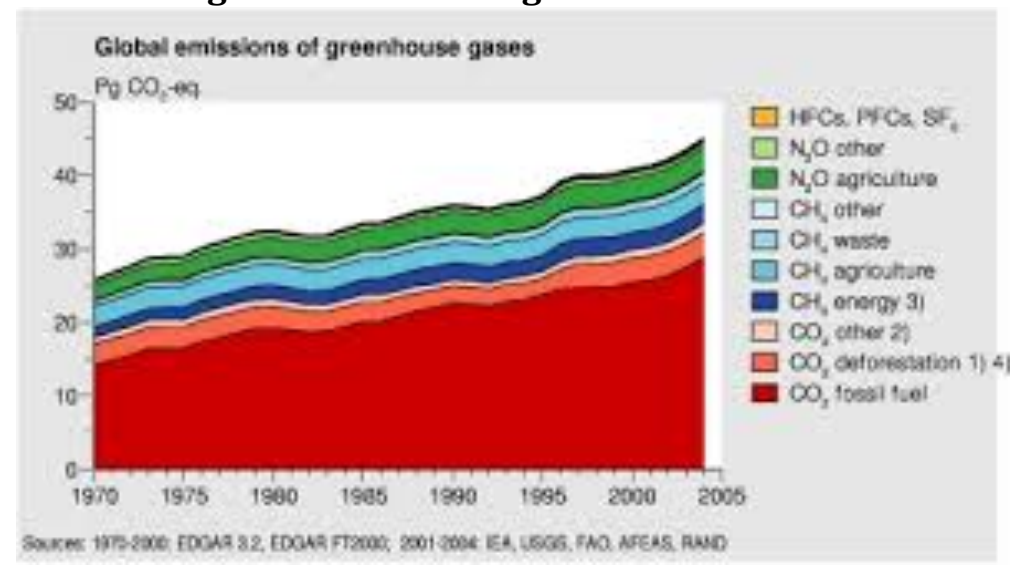


It is the carbon dioxide emission that has kept going up to a level of 50 trillion tonnes in 2013. Planet Earth can absorb less and less of these outputs, especially as global forests are decreasing and the acidification of the oceans increase.

It is often argues thet it is the yearly increase in these emissions that must be halted though a common pool global policy. Wrong! It is the total size in gigatons - the level and not the change - that is extremely worrisone for the future and mankind and his/her social systems as well as nature itself.

\section{b) The Links: GDP- Energy - Emissions}

What makes the process of global warming seemingly unstoppable is that it is driven by the most mundane incentive among human being, the quest for income and wealth. In order to produce decent living conditions, men and women search for economic development or the growth in GDP. Yet, Figure 3 shows that on the global macro level, the variation in economic development has strong implications for the emission of all kinds of greenhouse gases: the richer and larger a country economy, the more emissions it releases. This finding is, of course, the rationale for the argument that we need another kind of economic growth that builds upon carbon neutral technology. This is no doubt feasible in theory, but in practice we are stuck with the fossil fuel economy. And the destruction of forests and fresh water sources continue.

Figure 3. Total emissions and GDP: Equation: LN GDP - LN GHG Total : $y=0.81 x, R 2=0.708$

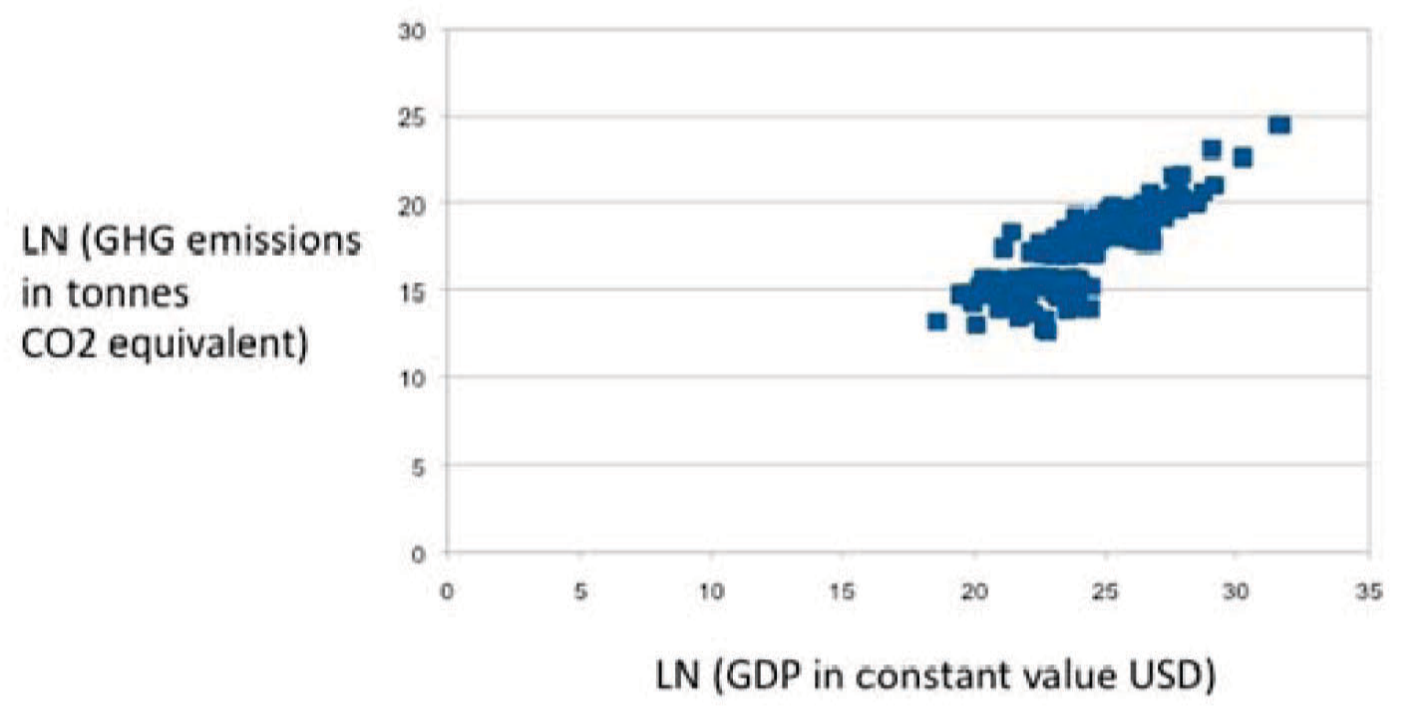

Note. GDP vs. Greenhouse emissions for 158 countries in 2011. Sources: 1. World Bank Open Data, http://data.worldbank.org. 2. CAIT WRI 2.0: Climate Data Explorer, World Resources Institute, http://cait2.wri.org

At global reunions among the politicians and experts, there is much talk about the emissions per capita. Developing countries underline that they tend to display lower emissions per capita than advanced economies. But total emissions count for the policy aim of reducing considerably the poisoning of the atmosphere!

Economic development can, I emphasize again, be environmental friendly. Many micro projects have reduced carbon emissions and yet delivered goods and services more efficiently. However, what counts at the macro level is the overall addition and subtractions. Take the 
example for Singapore that is well aware of the energy-environmental conundrum. Although it must be admitted that Singapore is doing many advanced projects to promote ecological sustainability, it should be pointed out that it is a big hub for air traffic and see shipping, which both result in greenhouse gases. In addition, Singapore has coal fired power stations and consumer huge amounts of electricity (water cleaning, waste treatment, air conditioning in almost all housing and public buildings).

The same contradictory finding applies to the UAE where lots of investments are done in ecologically friendly projects. But the fact remains that $\mathrm{CO} 2$ emissions per capita here are the largest in the world, like Qatar. To understand the close link between total GDP and total emissions one needs to look at global energy consumption.

Economic activity in all forms consumes directly or indirectly huge amounts of energy. This leads to the emission of greenhouse gases, directly or indirectly. To take a somewhat drastic example: the rapid increase in consumption of meat energy has resulted in an enormous growth of the number of cows in the world, which produce methane that is very conducive to climate change and global warming.

It is also the case that rich countries consume more energy per person than poor countries, as higher levels of affluence require more energy - in general. Again, the situation is paradoxical, as rich countries can invest in environment friendly technology but they also consume more energy for upholding their lifestyle. Figure 4 has the finding.

Figure 4. Total greenhouse gases and total energy consumption: Equation: Energy - emissions: $y$ $=1,223 x, R 2=0,616, N=173$

\section{LN (GHG Emissions / Tonnes $\mathrm{CO} 2$ eq.)}

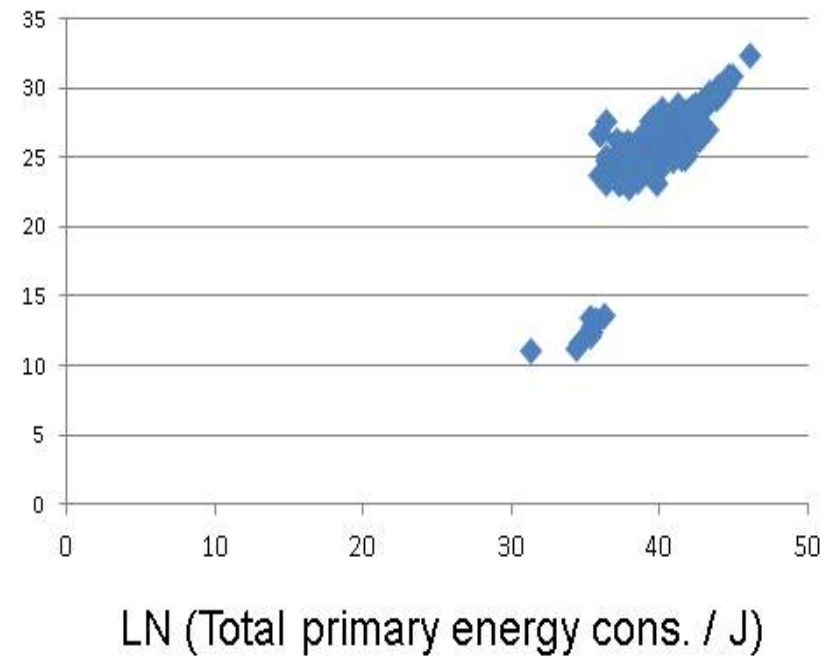

It is evident from the Figure 4 above that efforts should be undertaken to shift towards energy from carbon neutral sources, including reducing the greenhouse gases from fossil energy sources. If Shanghai can build a coal fired power station with no carbon dioxide emissions, then so can all Chinese cities or villages.

The combination of the choice of resilience in the basic game against Nature with the accumulation of massive transaction costs at global reunions leads only to the rapid decline in overall environmental capital. Ecology capital decreases, because there is no owner, mankind being just represented by some 190 governments in chaotic social choice settings at various places around the globe. 


\section{c) The 2012 Evidence}

In the most recently available macro data, one finds strong confirmation of the hypotheses launched above. It is an undeniable but badly neglected fact that the variation in the country emissions of greenhouse gases is very much a function of the GDP of the country economy! See Figure 5!

Figure 5. Country GDP and country emission of greenhouse gases 2012. Equation: $y=0.85 x$, $\mathrm{R} 2=\mathbf{0 . 8 0 4}$

LN

(Total GHG Emissions / Kg) $\mathrm{CO} 2$ equivalent

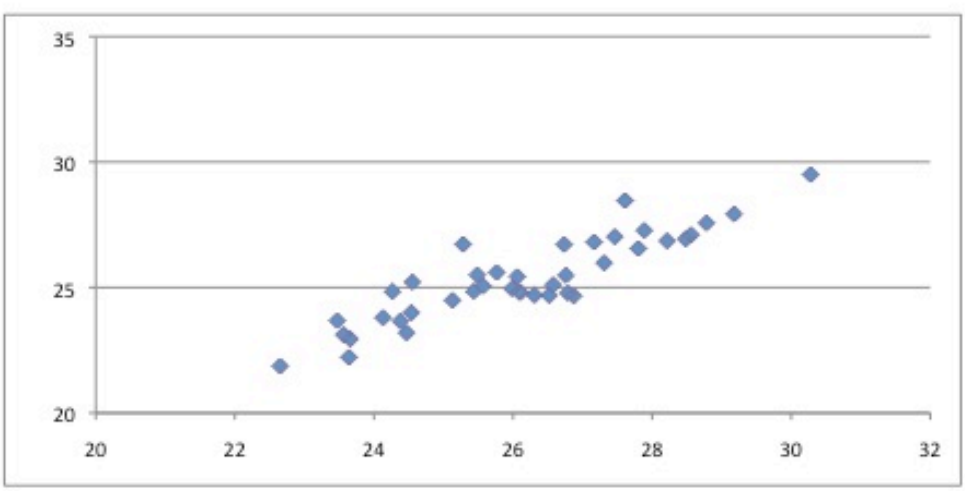

LN ( GDP / USD) (constant value 2005)

Sources: a) World Bank nattional accounts data, b) OECD National Accounts Data Files, c) United Nations Framework on Climate Change GHG inventory submissions.

The bigger the economy, the larger the emissions. This means that rich countries with a substantial population as well as medium income countries or even low income countries with huge population display the largets emissions. It also implies that when affluence goes up, emissions also increase. What is at stake is the life-style: cars, infrastructure (cement), urban centres (cement), air traffic, containers and fishing fleets, air-conditioning, food from cows, irrigation, etc., etc.

The core of the country economy is the use of various energy sources to produce goods and services for the global metket economy. And most energy is derived from the burning of fossil fuels. One had hope that there would soom come a global Hubbert peak for global oil production, but the massive exploitation of shale oil in the US and oil sands in Canada has made oil supply larger than demand. It is true that lots of experiments are goind on with renewable energy sources, but they do not change the overall trend in energy consumption - see Figure 6. 
Figure 6. Energy and GDP 2012 at country level. Equation: $y=0.88 x, R 2=0.908$

LN

(Total Energy Usage / Kg)

oil equivalent

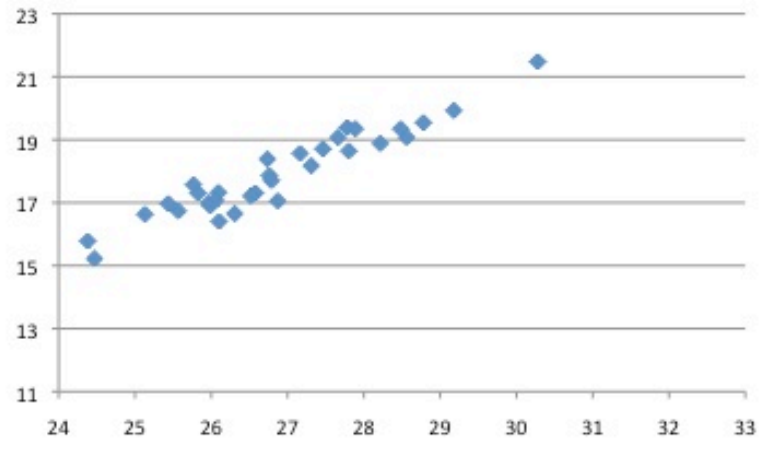

LN ( GDP / USD) (constant value 2005)

Sources: a) World Bank nattional accounts data, b) OECD National Accounts Data Files, c) International Energy Agencey Statistics.

From the perspective of global policy-making, the total emissions must decrease. And this not ocurring, despite all micro experiments. The macro trend appears in Figure 7.

Figure 7. Emissions - energy at country level. Equation: $y=1.05 x$ R2=0.941

LN

(GHG Emissions/ Kg)

$\mathrm{CO} 2$ equivalent

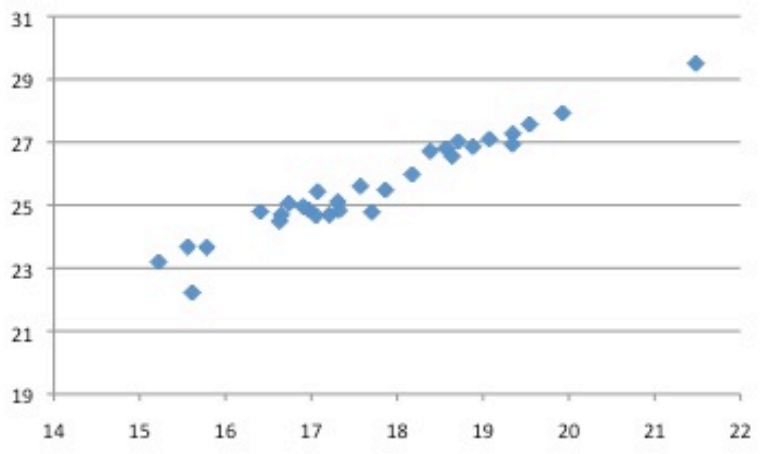

LN (Total Energy Usage / Kg) oil equivalent

Sources: a) International Energy Agencey Statistics, b) United Nations Framework on Climate Change GHG inventory submissions.

The basic theory here links global warming with the size of the GDP , i.e the level of affluence in the economy times the size of the population. This entails among other facts that the emission of greehouse gases must have exploded in Eastm South and South East Asia during the recent 25 years. Becoming the factory of the planet with enormous increases in affluence, the environment in this region of the world has deteriorated, as the major priority is economic growth.

Let us look at data about the vibrant Asian region, where average temperatures now require the massive use of airconditioning, which increases emissions and requires more energy!

ECOLOGY: Demand (pollution) and Supply (bio-capacity) 
There is no one single indicator on Planet's loss of environmental capital. The so-called Ecological Footprint Framework (EFF) launched an ambitious attempt to come up with a single measure on the supply of environmental resources and the demand for them by using the socalled "global hectar per capita measure (http://www.eea.europa.eu/highlights/Ann1132753060).

The idea to have most general or encompassing measure on both environmental capital (supply) and human pollution (demand) is an interesting one. But it is not easy to devise or calculate such a measure. Based on an enormous input of information and effort, these environmentalists come up with what is basically an economic type model with supply and demand.

The conclusion that Planet Earth and thus mankind is running a serious and increasing deficit between demand and supply, resulting in an increasing reduction of global ecological capital. This framework is no doubt ingenious, attempting to cover all aspects and dimensions of environmental capital. But there are some problems here in the EF approach.

Table 1 shows such a footprint analysis for demand and supply for some Asian countries, employing per capita measures only, according to the Global Footprint Framework (2009). 
Table 1. EAST ASIA and OCEANIA: Total Ecological Footprint, Bio-capacity and Net Result for 2005

\begin{tabular}{|c|c|c|c|}
\hline & \begin{tabular}{|l|} 
Total per capita \\
Ecological Footprint \\
\end{tabular} & \begin{tabular}{|l} 
Total per capita \\
Bio-capacity
\end{tabular} & $\begin{array}{l}\text { Ecological Deficit or } \\
\text { Reserve }\end{array}$ \\
\hline Australia & 7.8 & 15.4 & 7.6 \\
\hline Bangladesh & 0.6 & 0.3 & -0.3 \\
\hline Bhutan & 1.0 & 1.8 & 0.8 \\
\hline Cambodia & 0.9 & 0.9 & -0.0 \\
\hline China & 2.1 & 0.9 & -1.2 \\
\hline India & 0.9 & 0.4 & -0.5 \\
\hline Indonesia & 0.9 & 1.4 & 0.4 \\
\hline Japan & 4.9 & 0.6 & -4.3 \\
\hline Korea DPRP & 1.6 & 0.6 & -0.9 \\
\hline Korea Republic & 3.7 & 0.7 & -3.0 \\
\hline Laos & 1.1 & 2.3 & 1.3 \\
\hline Malaysia & 2.4 & 2.7 & 0.3 \\
\hline Mongolia & 3.5 & 14.6 & 11.2 \\
\hline Myanmar & 1.1 & 1.5 & 0.4 \\
\hline Nepal & 0.8 & 0.4 & -0.4 \\
\hline New Zealand & 7.7 & 14.1 & 6.4 \\
\hline Pakistan & 0.8 & 0.4 & -0.4 \\
\hline Papua New Guinea & 1.7 & 4.4 & 2.8 \\
\hline Philippines & 0.9 & 0.5 & -0.3 \\
\hline Singapore & 4.2 & 0.0 & -4.1 \\
\hline Sri Lanka & 1.0 & 0.4 & -0.6 \\
\hline Thailand & 2.1 & 1.0 & -1.2 \\
\hline Vietnam & 1.3 & 0.8 & -0.5 \\
\hline
\end{tabular}

Source: GFN 2009

Matters are complex, although the ecological footprint is much bigger per capita in richer countries than in poorer ones, with country specific factors playing a large role in shaping eventual surpluses or deficits. Overall, it seems that ecological footprints vary positively with country affluence, while bio-capacity is determined by a host of other factors besides affluence. But when country size is added to the equation, the numbers in Table 1 are totally transformed and quite another picture emerges - see Table 2. What matters crucially is the size of the country in terms of the number of inhabitants. 
Table 2: Total Ecological Impact (Deficit/Surplus/Person X Population) 2005

\begin{tabular}{|l|c|}
\hline Australia & 153.5 \\
\hline Bangladesh & -42.5 \\
\hline Bhutan & 1.8 \\
\hline Cambodia & -0.0 \\
\hline China & -1588.0 \\
\hline India & -551.7 \\
\hline Indonesia & 89.1 \\
\hline Japan & -550.8 \\
\hline Korea DPRP & -20.2 \\
\hline Korea Republic & -143.4 \\
\hline Laos & 7.7 \\
\hline Malaysia & 7.6 \\
\hline Mongolia & 29.1 \\
\hline Myanmar & 20.2 \\
\hline Nepal & -10.8 \\
\hline New Zealand & 25.6 \\
\hline Pakistan & -63.2 \\
\hline Papua New Guinea & -16.5 \\
\hline Philippines & -42.1 \\
\hline Singapore & \\
\hline Sri Lanka & -12.4 \\
\hline Thailand & -17.0 \\
\hline Vietnam & \\
\hline
\end{tabular}

Source: GFN 2009

When the total ecological imprint is estimated, taking population size into account, it is no longer tenable to argue that global ecological footprint follows affluence. On the contrary, poor or medium income countries with large populations may have much more ecological impact than small super affluent countries. China and India are big polluters in the Asia-Pacific region. Interestingly, although the average person in Papua New Guinea pollutes more than the average in Bangladesh, the total outcome is much more severe in the latter country, as the number of people is crucial when it comes to ecological footprint. Not surprisingly, the biocapacity of Papua New Guinea is larger than that of Bangladesh, which is vulnerable to flooding and hurricanes. It is possible to compare these scores for the Asia-Pacific region with comparable scores for other regions of the world. Table 3 attempts this, using the same framework of analysis. 
Table 3: Global Ecological Impact (Deficit/Surplus/person X population) 2005

\begin{tabular}{|l|c|}
\hline World & -3885.6 \\
\hline High Income Countries & -2624.4 \\
\hline Middle Income Countries & 0.0 \\
\hline Low Income Countries & -237.1 \\
\hline Africa & 360.8 \\
\hline Middle East and Central Asia & -365.6 \\
\hline Asia-Pacific & -2849.6 \\
\hline Latin America and the Caribbean & 1327.7 \\
\hline North America & -892.4 \\
\hline Europe (EU) & -1169.5 \\
\hline Europe (Non-EU) & 551.1 \\
\hline
\end{tabular}

Source: GFN 2009

The positive numbers for Latin America include the high bio-capacity for Brazil, Bolivia and Peru - numbers that will go down quickly in the future as the rain forest disappears. The same applies to Malaysia where the rain forest in Borneo is decimated every day.

\section{CONCLUSION}

A major source of conflict is the confusion of greenhouse gases per capita and total emissions, which has bearing upon the distribution of costs with any common ecology policy. In the debate about greenhouse gases and $\mathrm{CO} 2$ emissions, one tends to mix up the basic numbers. It is vital to distinguish between total emissions and per capita emissions, when comparing countries in ecological policy-making. This confusion results from strategic gaming.

Let me first draw a picture of the total emissions by means of a list of the ones with most emissions, measured in millions of metric tons (Table 4). 
Table 4. Countries with most emissions of greenhouse gases (mt) 2010

\begin{tabular}{|c|c|c|}
\hline COUNTRY & Greenhouse gases & In per cent \\
\hline China & $9,679.30$ & 22.7 \\
\hline USA & $6,668.79$ & 15.6 \\
\hline EU - 28 members & $4,663.41$ & 10,9 \\
\hline India & $2,432.18$ & 5.7 \\
\hline Russia & $2,291.57$ & 5.4 \\
\hline Japan & $1,257.10$ & 2.9 \\
\hline Brazil & $1,104.64$ & 2.6 \\
\hline Indonesia & 814.71 & 1.9 \\
\hline Canada & 710.72 & 1.7 \\
\hline Iran & 698.38 & 1.6 \\
\hline Mexico & 681.87 & 1.6 \\
\hline South Korea & 661.69 & 1.6 \\
\hline Australia & 560.64 & 1.3 \\
\hline Saudi Arabia & 510.14 & 1.3 \\
\hline South Africa & 458.29 & 1.1 \\
\hline Ukraine & 380.89 & 0.9 \\
\hline Argentina & 363.79 & 0.9 \\
\hline Nigeria & 320.04 & 0.8 \\
\hline Pakistan & 304.85 & 0.7 \\
\hline Kazakhstan & 300.83 & 0.7 \\
\hline Venezuela & 284.99 & 0.7 \\
\hline Malaysia & 282.60 & 0.7 \\
\hline Taiwan & 278.34 & 0.7 \\
\hline Uzbekistan & 215.36 & 0.5 \\
\hline Total & & $83 \%$ \\
\hline
\end{tabular}

Source: http://en.wikipedia.org/wiki/List_of_countries_by_greenhouse-gas_emissions

The structure of total emissions of greenhouse gases for global policy-making entails that what a mere set of some 20 countries, responsible for about 80 per cent of them, do will decides the 
outcomes. Were they to reduce their emissions by 5 per cent a year, it would have a tremendous impact upon the risks of climate change. Total emissions are a function of huge economy, sizeable affluence and Soviet legacy. But instead the UN orchestrates mega reunions with all states of the world and confuses total emissions with emissions per capita.

Table 5 shows that the list of countries with very high CO2 emissions per person is very different from Diagram 1. It includes a number of tiny countries that are little relevant for the global policy aim to reduce emissions significantly, sooner rather than later.

\section{Diagram 2. Per capita emission}

GHG Emissions, 2010

(tonnes of $\mathrm{CO} 2$ equivalent per capita)

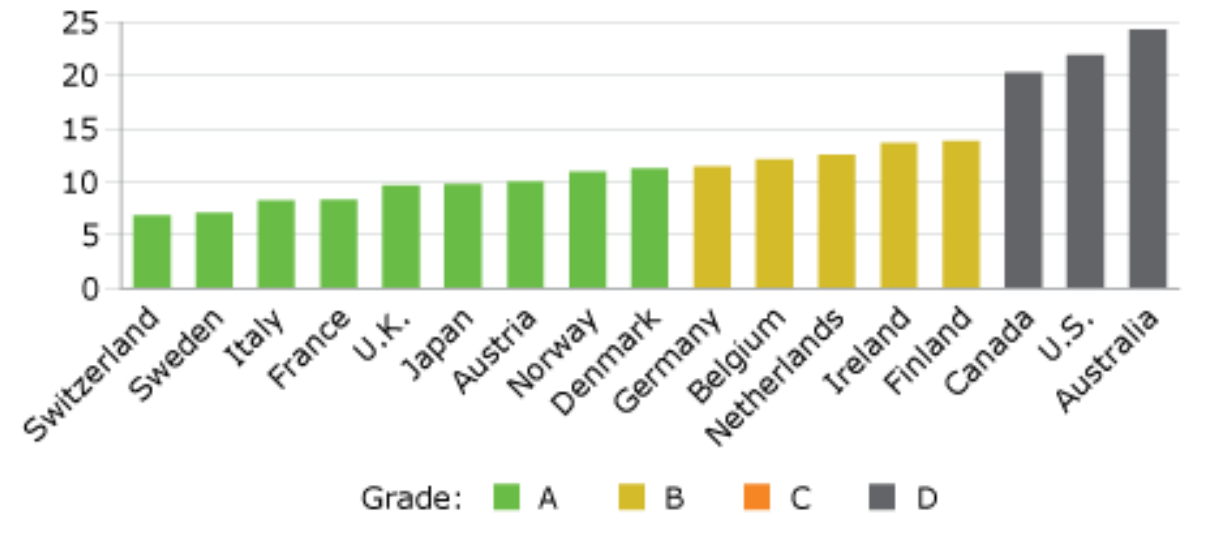

Source:http://www.conferenceboard.ca/hcp/details/environment/greenhouse-gasemissions.aspx

It may seem fair that all countries contribute to reduce greenhouse gases like CO2 emissions, but it is not efficient to focus upon emissions per capita.

There are several measures of per capita emissions in the literature. One may find diagrams with very high scores for the Gulf states - Qatar! - and Singapore, but they are tiny in a global context.

Climate change is finally getting the media attention it deserves, given the risk of catastrophe involved for mankind. But it still does not score highest in the priorities of the governments of the world. Traditional economic growth trumps ecological concerns, and tradition foreign policy objectives occupy state leaders more than the decline of the planet's environment. Time is now of the essence in the effort to arrive at global coordination reducing the emission of greenhouse gases substantially. Most important is the ecology policy of China. Why focus on the islands in South China Sea, which will be flooded or cementing Pakistan when so much could be done at home concerning the rebuilding of coal fired power stations?

\section{References}

Global Footprint Network 2009: http://www.footprintnetwork.org/en/index.php/GFN/ (last accessed 24/3 2009).

The European Environment Agency in coordination with Global Footprint Network: The National Ecological Footprint and Biocapacity Accounts, 2005 (Editionhttp://www.eea.europa.eu/highlights/Ann1132753060)

World Bank Open Data, http://data.worldbank.org.2.

CAIT WRI 2.0: Climate Data Explorer, World Resources Institute, http://cait2.wri.org. 
World Bank Data indicators, http://data.worldbank.org/indicator.

Energy consumption data: Energy data Global Statistical Yearbook. Retrieved from http://yearbook.enerdata.net.

EIA: Energy Outlook for 2014. Retrieved from http://www.eia.gov/forecasts/aeo/.

Greenhouse gas emission data: World Resources Institute CAIT2. Retrieved from http://cait2.wri.org.

Climate Change: Rising concentration of atmospheric greenhouse gases

http://www.dnrec.delaware.gov/ClimateChange/Pages/Risingconcentrationofatmosphericgreenhousegases.aspx

Butler, J.H. and S.A.Montzka THE NOAA ANNUAL GREENHOUSE GAS INDEX (AGGI): NOAA Earth System Research Laboratory, R/GMD, 325 Broadway, Boulder, C0 80305-3328,

http://www.esrl.noaa.gov/gmd/aggi/aggi.html.

Greenhouse Gas (GHG) Emissions. The Conference Board of Canada, 2015,

http://www.conferenceboard.ca/hcp/details/environment/greenhouse-gas-emissions.aspx.

Stern, N. (2007) The Economics of Climate Change: The Stern Review Paperback. Cambridge: Cambridge U.P. 